О. А. Руденко ${ }^{1}$ О. М. Одарущенкоํ, 3. М. Руденко ${ }^{3}$ О. Б. Одарущенко ${ }^{4}$

${ }^{1}$ Національний університет «Полтавська політехніка імені Юрія Кондратюка», Полтава, Україна

${ }^{2}$ Науково-виробниче підприємство «Радікс», Кропивницький, Україна

${ }^{3}$ Полтавський коледж нафти і газу національного університету «Полтавська політехніка імені Юрія Кондратюка», Полтава, Україна

${ }^{4}$ Полтавська державна аграрна академія, Полтава, Україна

\title{
ОЦНЮВАННЯ КІЛЬКОСТІ ВТОРИННИХ ДЕФЕКТІВ ПРОГРАМНИХ ЗАСОБІВ ШЛЯХОМ КОМПЛЕКСУВАННЯ МОДИФІКОВАНИХ МОДЕЛЕЙ РОСТУ НАДІЙНОСТІ ДЖЕЛІНСЬКІ-МОРАНДИ І ШИКА-ВОЛВЕРТОНА
}

\begin{abstract}
Анотац і я. Виконано аналіз множин моделей оцінювання надійності програмних засобів (МНПЗ) або за іноземною назвою моделей зростання надійності ПЗ (Software Reliability Growth Models - SRGM). Досліджено ймовірнісні МНПЗ з метою встановлення таких, що можуть бути використано для врахування фактору прояву вторинних дефектів. Під вторинними дефектами розуміються такі, що вносяться в ПЗ після усунення первинних, які проявляються та усуваються в процесі налагодження та тестування ПЗ. Проаналізовано припущення та аналітичні вирази моделей росту надійності програмних засобів Джелінські-Моранди, Шика-Волвертона, щодо питання їх застосування для врахування фактору внесення та прояву вторинних дефектів проектування програмних засобів. Запропоновано підхід щодо кількісної оцінки вторинних дефектів, що полягає в модифікації функцій ризику моделей внесенням до них параметра, який визначає число вторинних дефектів та комплексування модифікованих функцій ризику. Проаналізовані проблемні питання, що виникають при комплексуванні модифікованих простої експоненціальної моделі і моделі Джелінські-Моранди. Розглянуті підходи, при яких можливе комплексування модифікованих МНПЗ - узгодженість припущень, прийняття додаткових припущень, що узгоджують моделі, співставлення параметрів щодо умов здійснення аналітичних перетворень. Показані переваги комплексування модифікованих моделей росту надійності Джелінські-Моранди і Шика-Волвертона у порівнянні з комплексуванням модифікованої моделі росту надійності Джелінські-Моранди і модифікованої простої експоненціальної моделі. Проведено співставлення параметрів модифікованих моделей росту надійності Джелінські-Моранди і Шика-Волвертона, в результаті чого виявлено співпадання більшості з них. Додано припущення моделі росту надійності Шика-Волвертона про пропорційність функції ризику тривалості тестування, що не відповідає припущенню МНПЗ Джелінські-Моранди, оскільки відповідний параметр використовується в аналітичних перетвореннях при комплексуванні моделей. Обгрунтована можливість комплексування МНПЗ Джелінські-Моранди і Шика-Волвертона. Показана послідовність аналітичних перетворень об'єднаної моделі модифікованих моделей Джелінські-Моранди і Шика-Волвертона на основі яких одержана формула для оцінювання кількості вторинних дефектів програмних засобів. Одержаний вираз спрощує оцінювання кількості вторинних дефектів ПЗ, у порівнянні з їх оцінюванням на основі комплексування модифікованих моделей Джелінські-Моранди і простої експоненціальної моделі. Одержана формула у поєднанні з МНПЗ інших класифікаційних ознак дозволяє спрогнозувати значення функції ризику та далі використовувати ії для комплексного оцінювання показників надійності та функціональної безпеки складних систем, у тому числі систем, які можливо віднести до класу критичних (наприклад, програмно-технічних комплексів інформаційно-керуючих систем АЕC).

Кл юч ов і слов а: надійність програмного забезпечення, дефект, вторинний дефект, модель оцінювання надійності програмних засобів, модель Джелінські-Моранди, модель Шика-Волвертона, комплексування моделей, об’єднана модель Джелінські-Моранди і Шика-Волвертона.
\end{abstract}

\section{Вступ}

Впровадження інформаційних технологій у різноманітні галузі людської життедіяльності вимагає забезпечення високої якості програмного забезпечення, що використовується.

Дослідження проблем надійності програмного забезпечення ведуться великою кількістю вітчизняних на закордонних вчених, таких наприклад, як Ліпаєв В.В., Маєрс Г., Муса Дж. та ін. Одними із основних результатів цієї діяльності є розроблення множин моделей оцінювання надійності програмних засобів (МНПЗ) або за іноземною назвою моделей зростання надійності ПЗ (Software Reliability Growth Models - SRGM). Ці моделі у відповідності до прийнятих при їх розробці припущень дозволяють отримати оцінки такої властивості ПЗ як надійність. Актуальність та необхідність оцінювання цієї властивості ПЗ підтверджується рядом державних та міжнародних стандартів, наприклад ISO 25010 [2]. Моделі оцінювання надійності програмних засобів базуються на припущеннях, які визначають їх аналітичні вирази, що пов'язують параметри моделей. Але припущення не завжди адекватно відображають реалії етапів життєвого циклу програмних засобів. Дане дослідження стосується частини МНПЗ із множини ймовірнісних (Джелінські-Моранди та Шика-Волвертона). Одним з припущень, що містить ряд моделей, $\epsilon$ припущення про те, що дефекти постійно коректуються без внесення нових (моделі Джелінські-Моранди [3], Шика-Волвертона [4], проста експоненціальна модель [5] та ін.). В ряді інших моделей цей фактор взагалі не обумовлюється. Проте досвід розробки, налагодження та тестування ПЗ доводе, що в процесі усунення дефектів може бути внесено нові (умовно назвемо їх вторинними). Неврахування фактора внесення та прояву вторинних дефектів у процесі оцінювання показни- 
ків надійності може привести до одержання неточних результатів, або значних відхилень одержаних результатів від реальних.

Одним $з$ принципів кількісної оцінки вторинних дефектів є модифікація функцій ризику моделей шляхом внесення до них параметра, що визначає їх число. При цьому проводиться аналіз припущень моделей та аналітичних виразів функцій ризику на предмет можливості таких модифікацій. В [6-9] показана можливість модифікацій моделей Джелінські-Моранди, Шика-Волвертона, Ліпова та простої експоненційної моделі. Однак при знаходженні параметрів функцій ризику моделей одержуються системи рівнянь, що містять на одну невідому більше, ніж кількість рівнянь [8]. Тому однозначно кількість внесених дефектів визначити неможливо. Можливе комплексування з моделями інших класифікаційних груп для знаходження параметра - початкова кількість дефектів у програмі.

Одержання системи рівнянь у якій кількість рівнянь і невідомих однакова можливе при комплексуванні двох модифікованих моделей, як це показано на прикладі об’єднання модифікованої моделі Джелінські-Моранди та модифікованої простої експоненційної моделі [8]. Проте розв'язування одержаної системи у загальному вигляді пов'язане 3 проблемами технічного характеру: рівняння подані у неявному вигляді відносно змінної $K$ - коефіці$\epsilon$ нт пропорційності, шукана невідома $n^{B H}-$ кількість внесених дефектів знаходиться як у верхньому індексі знака суми так і під знаком диференціала. Складність одержаної системи рівнянь пояснюється, перш за все, достатньою складністю системи рівнянь для знаходження параметрів простої експоненційної моделі. Структура системи рівнянь для знаходження параметрів моделі Шика-Волвертона більш проста, ніж для простої експоненційної моделі.

При комплексуванні модифікованих моделей оцінки надійності програмних засобів крім співставлення параметрів моделей щодо можливості їх аналітичних перетворень важливою умовою $є$ узгодження припущень моделей. У цьому сенсі об'єднання модифікованої моделі Джелінські-Моранди та модифікованої простої експоненційної моделі обгрунтовується збігом припущень моделей за виключенням припущення про вигляд функції ризику в інтервалах між проявами дефектів, що в даному випадку не є принциповим.

Мета статті - одержання аналітичного виразу для оцінювання кількості вторинних дефектів програмних засобів на основі модифікованих моделей росту надійності Джелінські-Моранди і ШикаВолвертона шляхом їх комплексування.

\section{Основна частина}

Модель Джелінські-Моранди. Припущення моделі [5].

1 Інтенсивність виявлення дефектів $\lambda(t)$ (функція ризику) пропорційна поточній кількості дефектів у програмі, де поточна кількість це різниця між кількістю ДП ПЗ оцінена після завершення розробки
ПЗ та кількістю усунених (первинних) під час налагодження та тестування.

2 Прояв дефектів рівноймовірний і їх прояв не залежить один від одного.

3 Усі дефекти мають однакову складність.

4 Час до наступної відмови розподілений експоненціально.

5 Дефекти постійно коригуються без внесення нових.

6 Програмний засіб функціонує в середовищі близькому до реальних умов.

$7 \lambda(t)=$ const в інтервалі між двома суміжними моментами прояву дефектів.

Відповідно до цих припущень функція ризику подається у вигляді

$$
\lambda(t)=K(B-(i-1))
$$

де $t$ - довільний момент часу між виявленням $i-1$ го та $i$-го дефекту; $K$ - коефіцієнт пропорційності; $B$ - початкова (невідома) кількість дефектів у програмному засобі.

Таким чином, якщо за час $t$ було виявлено ( $i-1)$ дефектів, то в ПЗ ще залишається їх $B-(i-1)$.

Вважаючи $X_{i}=t_{i}-t_{i-1} \quad(i=\overline{1, n})$ і використовуючи четверте припущення можна стверджувати, що всі $X_{i}$ мають експоненціальний розподіл.

Модель Шика-Волвертона. Припущення:

1. Функція ризику пропорційна кількості дефектів у програмному засобі, а також, величині часу тестування.

2. Прояв дефектів рівноймовірний і незалежний.

3.Усі дефекти мають однакову складність.

4 Програмний засіб працює в умовах, близьких до реальних.

5 Дефекти постійно коригуються без внесення нових.

Функція ризику має такий вигляд:

$$
\lambda(t)=K(B-(i-1)) X_{i},
$$

де $X_{i}$ - час тестування, що минув від моменту $t_{i-1}$ виявлення $(i-1)$-го дефекту до поточного моменту $t_{i}, K$ - коефіцієнт пропорційності; $B$ - початкова (невідома) кількість дефектів у програмному засобі [4].

Припущення моделей Джелінські-Моранди і Шика-Волвертона фактично співпадають, за виключенням припущення про пропорційність функції ризику величині часу тестування.

Формули (1) і (2), що характеризують функції ризику моделей Джелінські-Моранди i ШикаВолвертона містять однакові параметри, за виключенням параметра $X_{i}$. В об'єднаній моделі слід прийняти припущення про пропорційність функції ризику тривалості тестування, оскільки аналітичні вирази містять цей параметр, а також, припущення про те, що на кожному часовому інтервалі виявляється один дефект. Вид розподілу часу між виявленням $i-1$-го та $i$-го дефекту у контексті задачі, що розглядається не $є$ принциповим. 
Виконаний аналіз припущень моделей Джелінські-Моранди і Шика-Волвертона дозволяє сформулювати висновок про їх узгодженість.

Урахування вторинних дефектів передбачає уточнення п'ятого припущення моделей у наступній редакції: дефекти постійно коригуються. Крім того, у функції ризику моделей додається параметр $n^{B H}$ - кількість внесених дефектів, внаслідок чого формули (1) і (2) відповідно набудуть вигляду

$$
\begin{gathered}
\lambda\left(t_{i}\right)=K\left(B-(i-1)+n^{B H}\right) \\
\lambda(t)=K\left(B-(i-1)+n^{B H}\right) X_{i} .
\end{gathered}
$$

На основі других припущень моделей одержані системи рівнянь для знаходження оцінки максимальної правдоподібності величин $K, B, n^{B H}$ моделей Джелінські-Моранди і Шика-Волвертона відповідно [7].

$$
\left\{\begin{array}{l}
K=\frac{n+n^{B H}}{\sum_{i=1}^{n+n^{B H}}\left(B-i+1+n^{B H}\right) X_{i}}, \\
\sum_{i=1}^{n+n^{B H}} \frac{1}{B-i+1+n^{B H}}=\frac{\left(n+n^{B H}\right)^{n+n^{B H}} \sum_{i=1}^{n+n^{B H}}\left(B-i+1+n^{B H}\right) X_{i}}{\sum_{i=1}^{B H}}, \\
\left\{\begin{array}{l}
n+n^{B H} \\
\sum_{i=1}^{n+n_{1}} \frac{\left.n-i+1+n^{B H}\right) \frac{X_{i}^{2}}{2}}{B-i+1+n^{B H}}=\frac{K^{n+n_{1}}}{2} \sum_{i=1}^{n} X_{i}^{2}
\end{array}\right.
\end{array}\right.
$$

3 урахуванням припущення про виявлення одного дефекту на кожному часовому інтервалі, в системі рівнянь (6) у верхньому індексі суми $n_{1}$ заміняється на $n^{B H}$.

$$
\left\{\begin{array}{l}
K=\frac{n+n^{B H}}{\sum_{i=1}^{n+n^{B H}}\left(B-i+1+n^{B H}\right) \frac{X_{i}^{2}}{2}}, \\
\sum_{i=1}^{n+n^{B H}} \frac{1}{B-i+1+n^{B H}}=\frac{K}{2} \sum_{i=1}^{n+n^{B H}} X_{i}^{2} .
\end{array}\right.
$$

Кожна 3 систем (5), (7) складається 3 двох рівнянь, у яких міститься три невідомих, що свідчить про те, що їх розв'язки не можна знайти однозначно.

В об’єднаній моделі маємо систему рівнянь, що складається з рівнянь систем (5), (7).

$$
K=\left(n+n^{B H}\right) / \sum_{i=1}^{n+n^{B H}}\left(B-i+1+n^{B H}\right) X_{i},
$$

$$
\begin{aligned}
& \sum_{i=1}^{n+n^{B H}} \frac{1}{B-i+1+n^{B H}}=\frac{\left(n+n^{B H}\right)^{n+n^{B H}} X_{i=1}}{\sum_{i=1}^{n+n^{B H}}\left(B-i+1+n^{B H}\right) X_{i}}, \\
& K=\frac{n+n^{B H}}{\sum_{i=1}^{n+n^{B H}}\left(B-i+1+n^{B H}\right) \frac{X_{i}^{2}}{2}}, \\
& \sum_{i=1}^{n+n^{B H}} \frac{1}{B-i+1+n^{B H}}=\frac{K^{n+n^{B H}}}{2} \sum_{i=1}^{{ }^{B}} X_{i}^{2} .
\end{aligned}
$$

Одержана система рівнянь має чотири рівняння при трьох невідомих, проте вираз

$$
\sum_{i=1}^{n+n^{B H}} \frac{1}{B-i+1+n^{B H}}
$$

при перетворенні системи слід виключити, оскільки невідомі, які він містить не можна виразити через інші невідомі.

Прирівнявши друге і четверте рівняння системи (8) виключаємо вираз (9). Маємо

$$
\left\{\begin{array}{l}
K=\frac{n+n^{B H}}{\sum_{i=1}^{n+n^{B H}}\left(B-i+1+n^{B H}\right) X_{i}}, \\
\frac{\left(n+n^{B H}\right)^{n+n^{B H}} \sum_{i=1} X_{i}}{\sum_{i=1}^{n+n^{B H}}\left(B-i+1+n^{B H}\right) X_{i}}=\frac{K^{2}}{\sum_{i=1}^{n+n^{B H}} X_{i}^{2}}, \\
K=\frac{n+n^{B H}}{\sum_{i=1}^{n+n^{B H}}\left(B-i+1+n^{B H}\right) \frac{X_{i}^{2}}{2}} .
\end{array}\right.
$$

Виключаємо $K$, співставляючи перше і третє рівняння системи (10). Маємо

$2 \sum_{i=1}^{n+n^{B H}}\left(B-i+1+n^{B H}\right) X_{i}=\sum_{i=1}^{n+n^{B H}}\left(B-i+1+n^{B H}\right) X_{i}^{2}$.

Проводимо перетворення рівності (11). Одержана формула містить шукану величину $n^{B H}$ у верхньому індексі сум. Тому додавання має здійснюватися до виявлення останнього дефекту. Інша невідома $B$ - початкова кількість дефектів у програмному засобі визначається з використанням моделей прогнозу потенційної кількості дефектів програмних засобів (наприклад, моделі Холстеда [10]):

$$
\begin{aligned}
& -2 \sum_{i=1}^{n+n^{B H}} i X_{i}+2\left(B+1+n^{B H}\right) \sum_{i=1}^{n+n^{B H}} X_{i}= \\
& =-\sum_{i=1}^{n+n^{B H}} i X_{i}^{2}+\left(B+1+n^{B H}\right) \sum_{i=1}^{n+n^{B H}} X_{i}{ }^{2} .
\end{aligned}
$$




$$
\begin{aligned}
\left(B+1+n^{B H}\right)\left(2 \sum_{i=1}^{n+n^{B H}} X_{i}-\sum_{i=1}^{n+n^{B H}} X_{i}^{2}\right)= \\
=2 \sum_{i=1}^{n+n^{B H}} i X_{i}-\sum_{i=1}^{n+n^{B H}} i X_{i}^{2} . \\
n^{B H}=\frac{\sum_{i=1}^{n+n^{B H}} i X_{i}^{2}-2 \sum_{i=1}^{n+n^{B H}} i X_{i}}{\sum_{i=1}^{n+n^{B H}} X_{i}^{2}-2 \sum_{i=1}^{n+n^{B H}} X_{i}}-B-1
\end{aligned}
$$

Отриманий результат (14) округлюється до цілих.

\section{Висновки}

Одержано аналітичний вираз для оцінювання кількості вторинних дефектів програмних засобів на основі комплексування модифікованих моделей
Джелінські-Моранди та Шика-Волвертона. Цей вираз значно спрощує оцінювання кількості вторинних дефектів ПЗ , у порівнянні з їх оцінюванням на основі комплексування модифікованих моделей Джелінські-Моранди і простої експоненціальної моделі. Даний вираз у поєднанні з МНПЗ інших класифікаційних ознак [5] дозволяє спрогнозувати значення функції ризику (інтенсивності прояву ДП П3, як функції часу) та далі використовувати її для комплексного оцінювання показників надійності та функціональної безпеки складних систем, у тому числі систем, які можливо віднести до класу критичних (наприклад, програмно-технічних комплексів інформаційно-керуючих систем АЕС).

Подальшими напрямками досліджень, спрямованих на одержання аналітичних виразів для оцінювання числа вторинних дефектів програмних засобів є аналіз можливості комплексування інших моделей, зокрема моделей, що належать до інших класифікаційних ознак.

\section{СПИСОК ЛІТЕРАТУРИ}

1. Гордеев А. А. Эволюция моделей качества программного обеспечения: методика и результаты анализа в контексте стандарта ISO 25010 / А.А. Гордеев, В.С. Харченко // Системы обработки информации. - 2013. - №6(113), С. 15-34.

2. International standard ISO/IEC FDIS 25010. System and software quality models. $-2010,34 \mathrm{p}$.

3. Jelinski Z. Software reliability research / Z. Jelinski, P. Moranda // Statistical computer performance evaluation W.Freiberger, Ed. Academic Press. - 1972. - P. 465-484.

4. Shick G.J. An analysis of computing software reliability models / G.J. Shick, R.W. Wolverton // IEEE Tras. Software Eng. V. SE-4. - № 2. - 1978. - P. 104-120.

5. Полонников Р.И. Методы оценки показателей надежности программного обеспечения / Р.И. Полонников, А.В. Никандров. - СПб.: Политехника $-1992 .-78 \mathrm{c}$.

6. Одарущенко О. Н. Учет вторичных дефектов в моделях надежности программных средств / О. Н. Одарущенко, А.А. Руденко, В.С. Харченко // Математичні машини і системи. - Київ: ІПММС НАН України, 2010. - № 1. - С. 205-217.

7. Анализ сценариев и определение параметров для оценки надежности программных средств с учетом вторичных дефектов / В.С.Харченко, О. Н. Одарущенко, А. А. Руденко, Е. Б. Одарущенко // Системи управління, навігації та зв'язку. - Київ, 2011. - Випуск 2 (18). - С.273-280.

8. Харченко В. С. Учет фактора вторичных дефектов при оценке надежности программных средств / В.С.Харченко, А. А. Руденко, О.Н.Одарущенко, Е. Б. Одарущенко // Научные ведомости Белгородского государственного университета. История. Политология. Экономика. Информатика. - Белгород, 2013. - № 22 (165). Выпуск 28/1. - С. 153-160.

9. Одарущенко О.Н. Метод оценивания надежности программных средств с учетом вторичных дефектов / О.Н. Одарущенко, А.А. Руденко, В.С. Харченко // Радіоелектронні і комп’ютерні системи. - 2012. - № 7 (59). - С. $294-300$.

10. Холстед М.Х. Начало науки о программах / М. Х. Холстед-М.: Финансы и статистика, 1981. - 128 с.

Received (Надійшла) 11.12.2019

Accepted for publication (Прийнята до друку) 29.01.2020

\section{Assessment of the number of secondary software defects based on combining the parameters of the Jelinski-Moranda and Shick-Wolverton software reliability growth models}

O. Rudenko, O. Odarushchenko, Z. Rudenko, O. Odarushchenko

Abstract. Software Reliability Growth Models (SRGM) have been investigated to identify those that can be used to account for the factor of manifestation of secondary defects. The secondary defects are those that are introduced into the software after the removal of the primary ones, which are introduced and eliminated during software debugging and testing. The assumptions and analytical expressions of the Jelinski-Moranda, Schick-Wolverton SRGM on the question of their application for the consideration of the secondary defects of software design are analyzed. An approach is proposed to quantify the secondary defects, which is to modify the risk functions of the SRGM. The problematic issues arising from the complexisation of the modified simple exponential model and the Jelinski-Moranda model are analyzed. Approaches in which the modification of SRGM is possible - consistency of assumptions, acceptance of additional assumptions that agree on models, comparison of parameters regarding the conditions of implementation of analytical transformations are considered. The advantages of combining Jelinski-Moranda and Schick-Wolverton SRGM compared to combining a modified Jelinski-Moranda model and a modified simple exponential model are presented. The resulting formula, in conjunction with SRGM other classification features, allows to predict the value of the risk function and further use it to comprehensively evaluate the reliability and functional safety of complex systems, including systems that can be attributed to the class of critical (eg, Instrumentation and Control Systems for Nuclear Power Plants).

Keywords: software reliability, defect, secondary defect, Software Reliability Growth Models, modified JelinskiMoranda reliability growth model, modified Shick-Wolverton reliability growth model, model aggregation, combined JelinskiMoranda and Shick-Wolverton model. 